This item was submitted to Loughborough's Research Repository by the author.

Items in Figshare are protected by copyright, with all rights reserved, unless otherwise indicated.

Forecasting the spot prices of various coffee types using linear and nonlinear error correction models

PLEASE CITE THE PUBLISHED VERSION

LICENCE

CC BY-NC-ND 4.0

REPOSITORY RECORD

Milas, Costas, Jesus Otero, and Theodore Panagiotidis. 2019. "Forecasting the Spot Prices of Various Coffee Types Using Linear and Non-linear Error Correction Models”. figshare. https://hdl.handle.net/2134/355. 
This item was submitted to Loughborough's Institutional Repository by the author and is made available under the following Creative Commons Licence conditions.

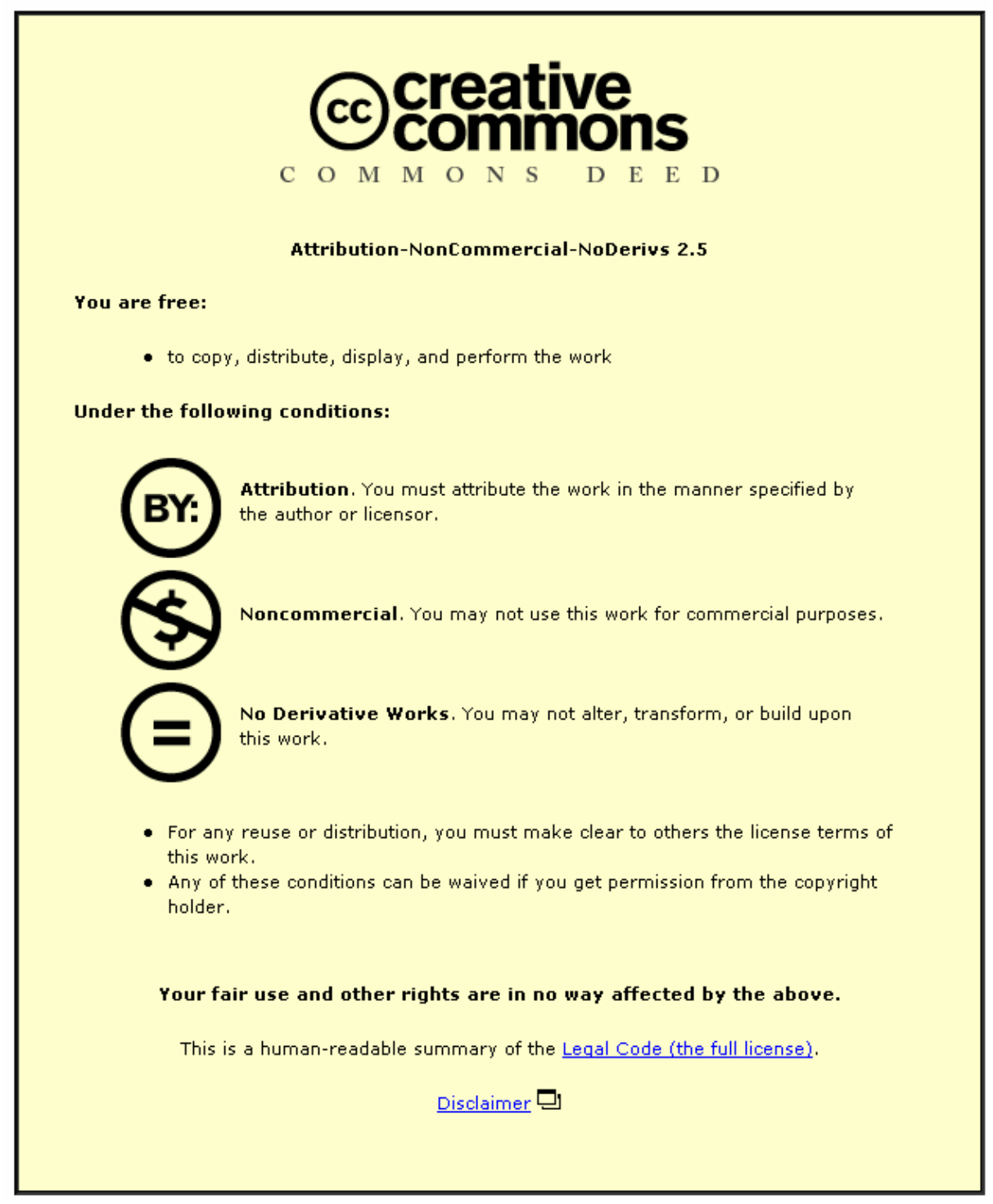

For the full text of this licence, please go to: http://creativecommons.org/licenses/by-nc-nd/2.5/ 


\title{
FORECASTING THE SPOT PRICES OF VARIOUS COFFEE TYPES USING LINEAR AND NON-LINEAR ERROR CORRECTION MODELS
}

\author{
Costas Milas \\ Department of Economics \\ City University, UK \\ $\square$ c.milas@city.ac.uk
}

\author{
Jesús Otero \\ Facultad de Economía \\ Universidad del Rosario, Colombia \\ 『jotero@claustro.urosario.edu.co
}

\author{
Theodore Panagiotidis* \\ Department of Economics \\ Loughborough University, UK \\ $\nabla$ t.panagiotidis@lboro.ac.uk
}

\begin{abstract}
This paper estimates linear and non-linear error correction models for the spot prices of four different coffee types. In line with economic priors, we find some evidence that when prices are too high, they move back to equilibrium more slowly than when they are too low. This may reflect the fact that, in the short run, it is easier for countries to restrict the supply of coffee in order to raise prices, rather than increase supply in order to reduce them. Further, there is some evidence that adjustment is faster when deviations from the equilibrium level get larger. Our forecasting analysis suggests that asymmetric and polynomial error correction models offer weak evidence of improved forecasting performance relative to the random walk model.
\end{abstract}

JEL classifications: C32, C51, C52, C53

Keywords: Coffee prices, asymmetric and polynomial error correction models, forecasting

* Corresponding author: Theodore Panagiotidis, Department of Economics, Loughborough University, Loughborough LE11 3TU, UK, email t.panagiotidis@lboro.ac.uk

The second author (Jesus Otero) acknowledges financial support from the Colombian National Federation of Coffee Growers. We would also like to thank an anonymous referee, Jeremy Smith, Timo Teräsvirta, and participants at the 2002 European Meeting of the Econometric Society (ESEM) conference in Venice for their most useful comments and suggestions. Any remaining errors are ours. 
Non-technical summary

The exports of many developing countries are often concentrated on a relatively small number of primary commodities, whose international prices are highly volatile. Dealing with large fluctuations in commodity prices certainly represents a challenge from a policy perspective, as the mismanagement of commodity booms and slumps may constitute a significant source of macroeconomic instability.

Among agricultural commodities, coffee is the major source of export revenue for lowand middle-income countries. There are two important species of coffee that can be distinguished, namely Arabica (which accounts for more than $70 \%$ of the world coffee production) and Robusta. The best-known varieties of the former are Unwashed Arabicas (mainly coffee from Brazil, thereafter UA), Colombian Mild Arabicas (mainly coffee from Colombia, thereafter COL), and Other Mild Arabicas (mainly coffee from other Latin American countries, thereafter OM), whereas Robusta coffee (thereafter ROB) is mainly grown in African countries and Southeast Asia.

We examine the relationships among the coffee prices above allowing for the possibility of non-linear adjustment back to equilibrium in the short-run behaviour of the four coffee prices. The adoption of a non-linear framework can be motivated by the fact that relative price increases in periods of a boom seem higher than relative price decreases in periods of a slump. In addition, there have been periods of time when the market operated under conditions of international agreements, which restricted exports, and periods of time when the market operated freely. Therefore, the behaviour of coffee prices may differ from one period to another.

We also evaluate the forecasting performance of the coffee price models. Forecasting variations in the price of coffee is particularly important for countries that rely on exports of this commodity as a source of foreign exchange. At the macroeconomic level, accurate 
information about future coffee prices can help policymakers devise measures to smooth out the impact of such price fluctuations on the economy. Unforeseen booms or misconceptions about their duration can certainly complicate macroeconomic management. In some developing countries, for example, temporary commodity booms have been thought to be permanent, and so they have been typically accompanied by overspending booms that are fuelled not only by higher incomes, but also by the increased indebtedness that results from the country's improved access to international borrowing.

Our main results are summarised as follows. First, markets for different types of coffee are highly integrated as the long-run relationships among coffee prices are found to affect all different coffee types. Second, there is evidence that when prices are too high, they move back to equilibrium more slowly than when they are too low. Further, there is some evidence that adjustment is faster when deviations from the equilibrium level get larger. Third, non-linear asymmetric and non-linear polynomial models offer improved forecasting performance relative to the random walk model primarily for the case of Colombian Milds but not for the other coffee types. The (relatively) weak out-of-sample forecasting performance of the nonlinear models may be due to the fact that non-linearity is not present in the forecast period. Alternatively, introducing different non-linear structure in coffee price models could improve their forecasting performance. 


\section{Introduction}

The exports of many developing countries are often concentrated on a relatively small number of primary commodities, whose international prices are highly volatile. Indeed, primary commodities, unlike manufactures, usually have low supply and demand price elasticities (in absolute value), so that a given shift in one of the curves causes a much larger change in prices compared with the case where the elasticities are larger in absolute value. Dealing with large fluctuations in commodity prices certainly represents a challenge from a policy perspective, as the mismanagement of commodity booms and slumps (i.e. sharp price rises or falls over a relatively short period of time) may constitute a significant source of macroeconomic instability.

Among agricultural commodities, coffee is the major source of export revenue for lowand middle-income countries (Varangis et al., 1995). It is difficult to speak of an international coffee market in the strict sense of the term, since there are two important species of coffee that can be distinguished, namely Arabica (which accounts for more than $70 \%$ of the world coffee production) and Robusta. The best-known varieties of the former are Unwashed Arabicas (mainly coffee from Brazil, thereafter UA), Colombian Mild Arabicas (mainly coffee from Colombia, thereafter COL), and Other Mild Arabicas (mainly coffee from other Latin American countries, thereafter OM), whereas Robusta coffee (thereafter ROB) is mainly grown in African countries and Southeast Asia.

In an earlier study, Vogelvang (1992) investigated the existence of long-run relationships among the spot prices of the four types of coffee discussed above, traded in the New York market. This was done using quarterly data over the period 1960-1982. More recently, Otero and Milas (2001) and Milas and Otero (2002) re-examined the relationships among coffee prices. The former study is based on an extended sample period up to 1998, also allowing for 
the possibility of non-linear adjustment back to equilibrium in the short-run behaviour of the four coffee prices. The latter introduces a smooth transition vector error correction (STVECM) and uses the estimated cointegrating vectors as transition variables. In the case of the coffee market, the adoption of a non-linear framework to study price behaviour can be motivated by the fact that relative price increases in periods of a boom seem higher than relative price decreases in periods of a slump. In addition, there have been periods of time when the market operated under conditions of international agreements, which restricted exports, and periods of time when the market operated freely. Therefore, the behaviour of coffee prices may differ from one period to another.

The purpose of this paper is to perform an evaluation of the forecast performance of multivariate linear and non-linear (asymmetric and polynomial) error correction models of the spot prices of the four coffee types discussed above. Forecasting variations in the price of coffee is particularly important for countries that rely on exports of this commodity as a source of foreign exchange. At the macroeconomic level, accurate information about future coffee prices can help policymakers devise measures to smooth out the impact of such price fluctuations on the economy. Unforeseen booms or misconceptions about their duration can certainly complicate macroeconomic management. In some developing countries, for example, temporary commodity booms have been thought to be permanent, and so they have been typically accompanied by overspending booms that are fuelled not only by higher incomes, but also by the increased indebtedness that results from the country's improved access to international borrowing. ${ }^{1}$

\footnotetext{
1 The problems arising from commodity booms have been widely discussed in the development economics literature, and are often known as "Dutch disease". This term refers to the fact that during the 1960s, Dutch manufacturing suffered from the appreciation of the real exchange rate that followed the discovery of natural gas in the North Sea. On the theoretical aspects of the Dutch disease literature see e.g. Corden and Neary (1982) and Neary and van Wijnbergen (1986). Varangis et al. (1995) focus on the management of commodity price volatility from the perspective of developing countries, examining and contrasting government policies and their effects.
} 
Our forecasting modelling exercise uses multivariate non-linear error correction models, which have been found to provide an appropriate framework for studying the behaviour of several macroeconomic time series; see e.g. Anderson (1997), and van Dijk and Franses (2000) for two recent applications of these models to the modelling of interest rates in the US and the Netherlands, respectively. Non-linear models are flexible as they allow us to examine the asymmetric effects of positive and negative deviations from equilibrium (sign effects) as well as the differential effects of small and large discrepancies (size effects). These differential effects might stem from the sunk costs of international arbitrage and the resulting tendency for traders to wait for sufficiently large arbitrage opportunities to open up before entering the market (see the discussion in Taylor et al, 2001). Despite these interesting properties associated with non-linear models, the question that needs to be answered is how successful they are for forecasting coffee prices (or the prices of other commodities). Examining the behaviour of four commodities that are important for many African economies (that is, cocoa, coffee, copper and cotton), Deaton (1992) found that neither linear univariate time series models, nor more elaborate structural models are very useful for predicting their prices. Our paper thus examines whether multivariate non-linear error correction models yield useful out-of-sample coffee price forecasts.

Our main results are summarised as follows. First, markets for different types of coffee are highly integrated as the long-run relationships among coffee prices are found to affect all different coffee types. Second, in line with economic reasoning, there is evidence that when prices are too high, they move back to equilibrium more slowly than when they are too low. Further, there is some evidence that adjustment is faster when deviations from the equilibrium level get larger. Third, asymmetric and polynomial models offer improved forecasting performance relative to the random walk model primarily for the case of Colombian Milds but not for the other coffee types. However, this should not deter us from employing non-linear 
models in empirical modelling. Economic priors suggest that non-linear models may be successful within the estimation sample. On the other hand, their (relatively) weak out-ofsample forecasting performance may be due to the fact that non-linearity is not present in the forecast period. Alternatively, introducing different non-linear structure in coffee price models could improve their forecasting performance.

The paper is organised as follows. Section II estimates the long-run relationships among the prices of different coffee types. Section III tests for asymmetric and polynomial adjustment in the behaviour of the coffee prices and discusses their out-of-sample forecasting performance. Finally, section IV offers some concluding remarks.

\section{Long-run estimates of coffee price models}

We have $p=4$ variables, $y_{t}=\left[P^{U A}, P^{O M}, P^{R O B}, P^{C O L}\right]^{\prime}$, where $P^{U A}, P^{O M}, P^{R O B}$ and $P^{C O L}$ are the logs of the spot prices of the different coffee types in the New York market. We use quarterly data from 1962(1) to 2001(1). The coffee prices are taken from the International Coffee Organisation (ICO). ${ }^{2}$ In our empirical work, we carry out our estimations over the period 1962(1)-1996(1), reserving the last five years of data for out-of-sample forecasting tests. Estimations are done in PcFiml 9.0 (Hendry and Doornik, 1997) and Eviews 4.0 (Quantitative Micro Software, 2001). In Johansen's $(1988,1995)$ notation, we write a $p$-dimensional Vector Error Correction Model (VECM) as:

$$
\Delta y_{t}=\sum_{i=1}^{k-1} \Gamma_{i} \Delta y_{t-i}+\Pi y_{t-1}+\mu+\varepsilon_{t}, t=1, \ldots, T
$$

where $\Delta$ is the first difference operator, $y_{t}$ is the set of $I(1)$ variables discussed above, $\varepsilon_{t} \sim \operatorname{niid}(0, \Sigma), \mu$ is a drift parameter, and $\Pi$ is a $(p \times p)$ matrix of the form $\Pi=\alpha \beta^{\prime}$, where $\alpha$ and $\beta$ are $(p \times r)$ matrices of full rank, with $\beta$ containing the $r$ cointegrating vectors and $\alpha$

\footnotetext{
${ }^{2}$ We would like to thank Ben Vogelvang for providing us with the pre 1983 dataset.
} 
carrying the corresponding loadings in each of the $r$ vectors.

Figure 1 plots the levels and the first differences of the four coffee price series. Preliminary analysis of the data using the Augmented Dickey-Fuller (ADF) tests suggested that all series are I(1) without drift when considered in levels. Applying the Johansen $(1988,1995)$ cointegrating approach to find the number of cointegrating vectors and using a lag length of $k=4$ in the linear $\mathrm{VAR},{ }^{3}$ the following vectors were identified:

$$
P^{C O L}=\quad \begin{array}{lcc}
0.304 P^{U A} & +0.672 P^{O M} & +0.183 \\
(0.056) & (0.062) & (0.052)
\end{array}
$$

and

$$
P^{R O B}=\quad P^{U A} \quad-0.247
$$

where standard errors are given in parentheses. ${ }^{4}$ The first vector involves $P^{C O L}, P^{U A}$ and $P^{O M}$. The estimated positive intercept supports the price differential of Colombian over the other Arabica coffee types (Colombian is regarded as a higher quality coffee). The second vector involves $P^{R O B}$ and $P^{U A}$. Here, the negative intercept proxies the quality premium of Unwashed Arabica over Robusta, since the latter is a lower quality of all four coffees. In the next section, we discuss linear and non-linear specifications of the error correction equations that will be used for forecasting analysis.

\footnotetext{
${ }^{3}$ We also allowed for three zero/one dummy variables. The first two (denoted by $d 1$ and $d 2$ ) capture moderate and grave frosts or droughts in the coffee areas, respectively, with information taken from ICO's web page, www.ico.org. In particular, $d 1$ takes the value of 1 in the third quarter of the years 1962, 1963, 1969, 1972, 1978, 1984,$1985 ; 1$ in the second quarter of the years 1967, 1979; 1 in 1985(4) and 1986(1); and 0 otherwise, whereas $d 2$ takes the value of 1 in the third quarter of the years 1966, 1975, 1981, 1994; 1 in the second quarter of the year 1994; and 0 otherwise. The third dummy (denoted by $d 893$ ) captures the collapse of the international coffee agreement in July 1989. Detailed cointegration results are available on request.

${ }^{4}$ For exact identification we imposed a unit coefficient on $P^{C O L}$ and a zero coefficient on $P^{R O B}$ in the first vector and a unit coefficient on $P^{R O B}$ and a zero coefficient on $P^{O M}$ in the second one. The unit coefficient on $P^{U A}$ and long-run exclusion of $P^{C O L}$ were tested in the second vector, producing a $\chi^{2}(2)=0.635(p$-value $=0.728)$.
} 


\section{Short-run estimates of coffee price models}

\section{III.1. In sample estimates}

OLS estimates of the error correction models are reported in the first panel of Table 1. To save space, we report only the estimated coefficients associated with the error correction terms. These are denoted by $C V 1_{\mathrm{t}-1}$ and $C V 2_{\mathrm{t}-1}$ and are given by equations (2) and (3), respectively. The other significant regressors appear in the notes of Table 1 . The results show significant feedbacks from both disequilibrium errors in the $\Delta P^{U A}$ and $\Delta P^{O M}$ equations. In addition, $C V 1_{\mathrm{t}-1}$ affects significantly $\Delta P^{R O B}$, whereas $C V 2_{\mathrm{t}-1}$ affects significantly $\Delta P^{C O L}$. A battery of diagnostic tests suggests some non-linear structure in the residuals of the estimated models. We postpone their discussion for the following section where we also provide evidence that a significant part of this non-linearity is captured by the employed non-linear specifications.

The literature on non-linearities in the behaviour of error correction models is now rich (see e.g. Granger and Lee, 1989; Granger and Teräsvirta, 1993; Escribano and Granger, 1998; Escribano and Pfann, 1998; and Escribano and Aparicio, 1999, among others). For instance, Granger and Lee (1989) partition the error correction term into its positive and negative components, and feed them back into the short-run dynamic equations (non-linear asymmetric model), whereas Escribano and Granger (1998) and Escribano and Aparicio (1999) use a cubic error correction term (non-linear polynomial model). This type of non-linear adjustment allows for a faster adjustment when deviations from the equilibrium level get larger.

The second and third panel of Table 1 report the asymmetric and polynomial error correction equations, respectively. First, as in Granger and Lee (1989), we take the deviations of $C V 1$ and $C V 2$ around their mean values, and partition them into their positive and negative components (denoted by $C V_{\mathrm{j}}^{+}$and $C V_{\mathrm{j}}^{-}, \mathrm{j}=1,2$, respectively). The results in the second panel of Table 1 indicate that the speed of adjustment varies depending on whether prices are above or below their 
equilibrium. For all equations, there is evidence that when prices are too high, they move back to equilibrium more slowly than when they are too low. This reflects the fact that, in the short run, it is easier for countries to restrict supply in order to raise prices, rather than increase supply in order to reduce them.

In the spirit of Escribano and Granger (1998) and Escribano and Aparicio (1999) we also allow for $C V_{\mathrm{j}}^{2}$ and $C V_{\mathrm{j}}^{3}(\mathrm{j}=1,2$, respectively) to enter the short-run equations. Our results in the last panel of Table 1 show some rather weak evidence that adjustment is faster when deviations from the equilibrium level get larger.

\section{III.2. In sample diagnostic checking}

Next we discuss some diagnostic checks which can be used to evaluate our estimated models. As can be seen from Table 1, the asymmetric and polynomial error correction models seem to capture some of the normality and heteroscedasticity failures that are present in the linear coffee price equations. As a further check for the adequacy of our asymmetric and nonlinear models, we examine their ability to capture all non-linear features of the first differences of the four coffee prices. This is done by applying three fairly general tests for remaining non-linearity to the residuals of the estimated models, namely the well-known Brock, Dechert and Sheinkman (1996, thereafter BDS) test, the bicovariance test due to Hinich (1996), and the Tsay (1986) test for quadratic serial dependence. In all cases, the null hypothesis of linearity is tested against an unspecified alternative. Ashley and Patterson (2001) offer a complete discussion of this group of tests. Taking into account that our sample

size is small and that a single non-linearity test can only detect or fail to detect non-linearity, the application of a battery of non-linearity tests can provide valuable non-linear identification information on a given time series. That said, Ashley and Patterson (2001, p. 20) point out, in line with previous literature, that "the BDS test is the best test of this group 
for use as a non-linearity screening test". The tests were estimated using the Non-linear Toolkit by Patterson and Ashley (2000) and BDS Stats 8.21 by Brock et al. (1996). Due to our small sample size, we follow Ashley and Patterson (2001) in computing the bootstrapped significance levels as well as those based on asymptotic theory.

For each of the four coffee price series, the tests are applied to the residuals of four different models that will be used for forecasting analysis in the next section, that is, a random walk model (i.e. a model where the only explanatory variable is the intercept term) and the linear, asymmetric and polynomial models of Table 1 . Results are reported in Table 2 . In the case of UA, the random walk and the non-linear polynomial specification are doing better than the other two models. On the other hand, there is strong evidence to suggest that the residuals of the polynomial and the asymmetric models for COL are i.i.d., that is, both models seem to be able to capture most of the non-linearities, therefore providing a good in-sample fit. In the case of OM, the polynomial specification produces higher BDS asymptotic $p$-values, thus providing evidence to suggest that the residuals of this model are i.i.d. At the same time, both the linear and the asymmetric model give much higher $p$-values than the random walk model. Last, the polynomial and the asymmetric models for ROB do not fail to capture the important non-linearities in the data generating process. ${ }^{5}$

The results from the Bicovariance and the Tsay test (see Table 3), are somewhat different from the BDS results, suggesting that non-linearity is not present in the residuals of the linear equations for $\mathrm{COL}, \mathrm{OM}$, and $\mathrm{ROB}$, respectively. However, they also suggest that compared to random walk models, the asymmetric model for COL and the polynomial and asymmetric models for OM succeed in capturing non-linearities.

\section{III.3. Out of sample forecasting performance}

\footnotetext{
${ }^{5}$ Bootstrapped BDS $p$-values are almost identical to the asymptotic $p$-values and for this reason not reported here.
} 
In order to assess the usefulness of our linear and non-linear error correction models, dynamic out-of-sample forecasts of the first differences of the four coffee prices are computed. These are compared with the forecasts of random walk coffee price models. Forecasting accuracy is evaluated using Mean Absolute Error (MAE) and Mean Square Error (MSE) criteria. Further, in order to assess the accuracy of the linear and non-linear models relative to the random walk models we employ the modified version of the Diebold and Mariano (1995) test as proposed by Harvey et al. (1997). Following Diebold and Mariano (1995), the time $t$ loss associated with a forecast (say $i$ ) is an arbitrary function of the realisation and prediction, $g\left(y_{t}, \hat{y}_{i t}\right)$. The loss function is a direct function of the forecast error, that is, $g\left(y_{t}, \hat{y}_{i t}\right)=g\left(e_{i t}\right)$. The null hypothesis of equal forecast accuracy for two competing forecasts is $\mathrm{E}\left[g\left(e_{i t}\right)\right]=\mathrm{E}\left[g\left(e_{j t}\right)\right]$, or $\mathrm{E}\left[d_{t}\right]=0$, where $d_{t} \equiv\left[g\left(e_{i t}\right)-g\left(e_{j t}\right)\right]$ is the loss differential (i.e. the difference between absolute or square forecast errors). Thus, the "equal accuracy" null hypothesis is equivalent to the null hypothesis that the population mean of the loss-differential series is 0 . Let $\bar{d}=\frac{1}{T} \sum_{t=1}^{T}\left[g\left(e_{i t}\right)-g\left(e_{j t}\right)\right]$ denote the sample mean loss differential (over $T$ forecasts), and let $g\left(e_{i t}\right)$ be is a general function of forecast errors (e.g. MAE or MSE). Then, $\sqrt{T}(\bar{d}-\mu) \stackrel{d}{\longrightarrow} N\left(0,2 \pi f_{d}(0)\right)$, where $N($.$) refers to the normal$ distribution. The Diebold and Mariano (1995) test is given by:

$$
D M=\frac{\bar{d}}{\sqrt{\frac{2 \pi \hat{f}_{d}(0)}{T}}} \stackrel{d}{\longrightarrow} N(0,1)
$$

where $\hat{f}_{d}(0)$ is a consistent estimate of the spectral density of the loss differential at frequency $0 .{ }^{6}$ To counteract the tendency of the $D M$ test statistic to reject the null too often

\footnotetext{
${ }^{6}$ In order to provide a consistent estimate of the spectral density, the appropriate truncation lag is chosen by examining the loss differential autocorrelation functions (see e.g. the discussion in Diebold and Mariano, 1995).
} 
when it is true, Harvey et al. (1997) propose a modified Diebold-Mariano test statistic:

$$
D M^{*}=\left[\frac{T+1-2 h+T^{-1} h(h-1)}{T}\right]^{1 / 2} D M \stackrel{d}{\longrightarrow} t_{(T-1)}
$$

where $D M$ is the original Diebold and Mariano (1995) test statistic for $h$-steps ahead forecasts and $t_{(T-1)}$ refers to Student's $t$ distribution with $(T-1)$ degrees of freedom.

Table 4 reports the MAE and MSE criteria for the different versions of the coffee price models. The statistical significance of the forecasting performance of the linear, asymmetric, and polynomial error correction models relative to random walk models, respectively, is examined using modified $D M^{*}$ tests. We examine the forecasting performance of the different models over a forecast horizon of $h=1$ quarter ahead. This is done for two reasons. Firstly, there is not evidence to suggest that non-linear models perform well for $\mathrm{h}>1$; Ramsey (1996) points out that forecasting inherently relies on the (unknown) global properties of the system and one-period-ahead forecasts rely least on them (see the discussion in Ramsey,1996 p.74). Secondly for $\mathrm{h}>1$ the forecasts are going to be regime-dependent in the case of the non-linear asymmetric model and require the use of simulation techniques (see Franses and van Dijk 2000, p118-121). According to our results, the asymmetric and polynomial error correction models offer improved forecasting performance relative to the random walk model primarily for the case of Colombian Milds. For all other coffee types, our linear, asymmetric and polynomial models cannot beat the random walk model. One possible explanation may have to do with what our results in section III.2 suggested; although our asymmetric and non-linear models are quite successful for Colombian Milds, there seems to be some remaining nonlinear structure in the residuals of the asymmetric and polynomial models of all other three coffee prices. Therefore, introducing different non-linear structures could possibly improve the forecasting performance of the coffee price models. ${ }^{7}$ Furthermore, although non-

\footnotetext{
${ }^{7}$ That said, the infinite set of non-linear models makes determination of a good approximation to the data
} 
linearities might be present and significant in our models, the latter may fail to produce ex ante forecast improvement; in other words, statistical significance does not imply economic significance (see e.g. Diebold and Nason, 1990). Therefore, the puzzle remains unsolved in the sense that in-sample non-linearities are not useful out-of-sample (see e.g. the discussion in Ramsey, 1996). Another possible explanation for the relatively poor forecasting performance of the non-linear models is that non-linearity is not present in the forecast period (see e.g. the discussion in van Dijk et al., 2002).

\section{Concluding remarks}

This paper has examined the price relationships between different types of coffees both in a linear and a non-linear environment. Using price data for Unwashed Arabicas (i.e. coffee from Brazil), Colombian Mild Arabicas (i.e. coffee from Colombia) Other Mild Arabicas (i.e. coffee from other Latin American countries) and Robusta coffee (i.e. coffee from Africa and Southeast Asia), we identified two cointegrating relationships affecting the short-run dynamics of the four coffee prices. Our estimates of the asymmetric and polynomial error correction models provided evidence that when the coffee prices are too high, they move back to equilibrium more slowly than when they are too low. At the same time, there is some evidence that adjustment is faster when deviations from the equilibrium level get larger.

Finally, our results suggested that non-linear error correction models offer very weak evidence of improved forecasting performance relative to the random walk model. However, this should not deter us from using non-linear models in empirical modelling. Economic priors suggest that non-linear models may be successful within the estimation sample. On the other hand, their (relatively) weak out-of-sample forecasting performance may be due to the fact that non-linearity does not show up in the forecast period. Alternatively, specifying

generating process a difficult task. 
different non-linear structures could possibly improve the forecasting performance of the coffee price models. It is notable that commenting on Ericsson et al.'s (1998) UK money demand model, Teräsvirta (1998) pointed out that non-linear models with quadratic and cubic error correction terms, are first-order approximations to smooth transition regressions (STR; see e.g. Granger and Teräsvirta, 1993), where the transition mechanism is driven by the disequilibrium error.

\section{References}

Anderson, H.M. (1997). "Transaction costs and nonlinear adjustment towards equilibrium in the US Treasury Bill market”, Oxford Bulletin of Economics and Statistics, 59, pp. 465484.

Ashley, R.A., and D.M. Patterson (2001). "Nonlinear model specification/Diagnostics: Insights from a battery of nonlinearity tests” Economics Department Working Paper E9905, Virginia Tech.

Brock, W.A., D.A. Hsieh and B. LeBaron (1991). Nonlinear Dynamics, Chaos and Instability, MIT Press, Cambridge.

Brock, W.A., W. Dechert, J. Scheinkman and B. LeBaron (1996). "A test for independence based on the correlation dimension”, Econometric Reviews 15, pp. 197-235.

Corden, M. and P. Neary (1992). "Booming sector and de-industrialisation in a small open economy”, Economic Journal 92, pp. 825-848.

Deaton, A. (1992). "Commodity prices, stabilisation, and growth in Africa", Research Program in Development Studies Discussion Paper \#166. Princeton University.

Diebold, F.X. and J. Nason (1990). "Nonparametric exchange rate prediction?", Journal of International Economics 28, pp. 315-332.

Diebold, F.X. and R.S. Mariano (1995). "Comparing predictive accuracy", Journal of 
Business and Economic Statistics 13, pp. 253-263.

Ericsson, N.R., D.F. Hendry and K.M. Prestwich (1998). "The demand for broad money in the United Kingdom, 1878-1993”, Scandinavian Journal of Economics 100, pp. 289-324.

Escribano, A. and C.W.J. Granger (1998). "Investigating the relationship between gold and silver prices", Journal of Forecasting 17, pp. 81-107.

Escribano, A. and F. Aparicio (1999). "Cointegration: linearity, nonlinearity, outliers and structural breaks". In Dahiya, S.B. (Ed.), The Current State of Economic Science, Spellbound Publications, Vol 1, pp. 383-407.

Escribano, A. and G.A. Pfann (1998). "Nonlinear error correction, asymmetric adjustment and cointegration”, Economic Modelling 15, pp. 197-216.

Franses, P.H. and D. van Dijk (2000), Non-linear time series models in empirical finance, Cambridge University Press, Cambridge.

Granger, C.W.J. and T. Teräsvirta (1993). Modelling Nonlinear Economic Relationships, Oxford University Press, Oxford.

Granger, C.W.J. and T.H. Lee (1989). "Investigation of production, sales and inventory relationships using multicointegration and non-symmetric error correction models", Journal of Applied Econometrics 4, pp. S145-S159.

Harvey, D., S. Leybourne and P. Newbold (1997). "Testing the equality of prediction mean squared errors", International Journal of Forecasting 13, pp. 281-291.

Hendry, D.F. and J.A. Doornik (1997). Modelling Dynamic Systems Using PcFiml 9.0 for Windows, International Thomson Business Press.

Hinich, M. (1996). "Testing for dependence in the input to a linear time series model", Journal of Nonparametric Statistics 6, pp. 205-221.

Johansen, S (1988). "Statistical analysis of cointegration vectors", Journal of Economic Dynamics and Control 12, pp. 231-254. 
Johansen, S. (1995). Likelihood-based Inference in Cointegrated Vector Autoregressive Models, Oxford University Press, Oxford.

Milas, C and Otero J. (2002), Smooth transition vector error correction models for the spot prices of coffee, Applied Economic Letters, 9, pp. 925-928.

Neary, P. and S. van Wijnbergen (1986). Natural resources and the macroeconomy: A theoretical framework. In Neary, P. and van Wijnbergen, S. (Eds.), Natural Resources and the Macroeconomy, Basil Blackwell Ltd, Oxford, pp. 13-45.

Otero, J. and C. Milas (2001). "Modelling the behaviour of the spot prices of various types of coffee", Economic Modelling 18, pp. 625-41..

Patterson, D.M. and R.A. Ashley (2000). A Nonlinear Time Series Workshop, Kluwer Academic Publishers, Boston.

Quantitative Micro Software (2001). Eviews 4.0.

Ramsey, J.B. (1996), "If nonlinear models cannot forecast, what use are they?", Studies in Nonlinear Dynamics and Econometrics 1(2), pp. 65-86.

Taylor, M.P., D. Peel and L. Sarno (2001), Nonlinear mena reversion in real exchange rates: toward a solution to the purchasing power parity puzzles, International Economic Review, 42(4), pp.1015-1042.

Teräsvirta, T. (1998). Comment on "The demand for broad money in the United Kingdom, 1878-1993" by Ericsson, N.R., D.F. Hendry and K.M. Prestwich, Scandinavian Journal of Economics 100, pp. 325-328.

Teräsvirta, T. and A.-C. Eliasson (2001). "Nonlinear error correction and the UK demand for broad money, 1878-1993”, Journal of Applied Econometrics 16, pp. 277-288.

Tsay, R.S. (1986). “Nonlinearity tests for time series”, Biometrika 73, pp. 461-466.

van Dijk, D. and P.H. Franses (2000). Nonlinear error-correction models for interest rates in the Netherlands. In Barnett, W.A., Hendry, D.F., Hylleberg, S., Teräsvirta, T., Tjostheim D., 
Würtz A. (Eds.), Nonlinear Econometric Modelling in Time Series Analysis, Cambridge: Cambridge University Press, pp. 203-227.

van Dijk, D., T. Teräsvirta and P.H. Franses (2002). Smooth transition autoregressive models - a survey of recent developments, Econometric Reviews 21, pp. 1-47.

Varangis, P., T. Akiyama and D. Mitchell (1995). "Managing commodity booms - and busts", World Bank, Washington DC.

Vogelvang, E. (1992). "Hypothesis testing concerning relationships between spot prices of various types of coffee", Journal of Applied Econometrics 7, pp. 191-201. 
Table 1. Error correction models

\begin{tabular}{|c|c|c|c|c|c|c|c|c|}
\hline \multirow[t]{2}{*}{ Variable } & \multicolumn{2}{|c|}{$\Delta P^{U A}$} & \multicolumn{2}{|c|}{$\Delta P^{C O L}$} & \multicolumn{2}{|c|}{$\Delta P^{O M}$} & \multicolumn{2}{|c|}{$\Delta P^{R O B}$} \\
\hline & Coeff. & S.E. & Coeff. & S.E. & Coeff. & S.E. & Coeff. & S.E. \\
\hline \multicolumn{9}{|c|}{$\underline{\text { Linear adjustment }}$} \\
\hline$C V 1_{t-1}$ & 0.760 & 0.237 & & & 0.622 & 0.267 & 0.708 & 0.217 \\
\hline$C V 2_{t-1}$ & 0.329 & 0.082 & 0.120 & 0.067 & 0.152 & 0.081 & & \\
\hline $\mathrm{F} a r$ & 1.148 & {$[0.338]$} & 0.568 & {$[0.687]$} & 0.601 & {$[0.663]$} & 0.394 & {$[0.813]$} \\
\hline$\chi^{2}$ nor & 11.466 & [0.003] & 11.577 & {$[0.003]$} & 3.525 & {$[0.172]$} & 4.844 & {$[0.089]$} \\
\hline $\mathrm{F}$ arch & 2.373 & {$[0.057]$} & 0.327 & [0.859] & 0.924 & {$[0.453]$} & 2.118 & {$[0.083]$} \\
\hline F het & 2.186 & {$[0.007]$} & 1.850 & {$[0.027]$} & 1.368 & {$[0.148]$} & 1.490 & {$[0.099]$} \\
\hline$\sigma$ & 0.119 & & 0.100 & & 0.115 & & 0.110 & \\
\hline \multicolumn{9}{|c|}{ Asymmetric adjustment } \\
\hline$C V 1_{t-1}^{+}$ & 0.248 & 0.428 & & & 0.280 & 0.438 & 0.121 & 0.393 \\
\hline$C V 1_{t-1}^{-}$ & 1.036 & 0.366 & & & 0.920 & 0.381 & 1.119 & 0.315 \\
\hline$C V 2_{t-1}^{+}$ & 0.184 & 0.162 & 0.035 & 0.135 & 0.220 & 0.158 & & \\
\hline$C V 2_{t-1}^{-}$ & 0.427 & 0.150 & 0.190 & 0.118 & 0.072 & 0.148 & & \\
\hline $\mathrm{F}$ ar & 1.370 & [0.249] & 0.345 & [0.847] & 0.704 & {$[0.591]$} & 0.374 & {$[0.827]$} \\
\hline$\chi^{2}$ nor & 7.723 & [0.021] & 11.265 & [0.004] & 3.332 & [0.189] & 6.221 & {$[0.045]$} \\
\hline $\mathrm{F}$ arch & 2.694 & {$[0.035]$} & 0.426 & {$[0.790]$} & 1.295 & {$[0.276]$} & 2.230 & {$[0.070]$} \\
\hline F het & 1.747 & [0.033] & 1.729 & [0.039] & 1.225 & {$[0.237]$} & 1.417 & {$[0.124]$} \\
\hline$\sigma$ & 0.118 & & 0.100 & & 0.114 & & 0.108 & \\
\hline \multicolumn{9}{|c|}{ Polynomial adjustment } \\
\hline$C V 1_{t-1}$ & 0.499 & 0.377 & & & 0.685 & 0.383 & 0.982 & 0.346 \\
\hline$C V 1_{t-1}^{2}$ & -3.093 & 2.209 & & & -1.971 & 2.192 & -4.117 & 1.963 \\
\hline$C V 1_{t-1}^{3}$ & -2.033 & 22.590 & & & -18.987 & 22.900 & -28.955 & 21.142 \\
\hline$C V 2_{t-1}$ & 0.085 & 0.127 & 0.057 & 0.105 & 0.013 & 0.127 & & \\
\hline$C V 2_{t-1}^{2}$ & 0.155 & 0.482 & -0.138 & 0.407 & 0.494 & 0.480 & & \\
\hline$C V 2_{t-1}^{3}$ & 3.332 & 1.614 & 0.723 & 1.350 & 2.503 & 1.601 & & \\
\hline $\mathrm{F} a r$ & 0.906 & [0.463] & 0.391 & [0.815] & 0.618 & {$[0.651]$} & 0.255 & {$[0.906]$} \\
\hline$\chi^{2}$ nor & 7.806 & [0.020] & 12.590 & [0.002] & 5.732 & {$[0.057]$} & 6.621 & {$[0.037]$} \\
\hline $\mathrm{F}$ arch & 1.639 & {$[0.170]$} & 0.371 & [0.829] & 0.792 & {$[0.533]$} & 2.327 & {$[0.061]$} \\
\hline $\mathrm{F}$ het & 1.521 & [0.079] & 1.565 & [0.072] & 1.038 & {$[0.432]$} & 1.322 & {$[0.173]$} \\
\hline$\sigma$ & 0.116 & & 0.100 & & 0.114 & & 0.108 & \\
\hline
\end{tabular}

Notes: S.E. are standard errors. $\sigma$ is the regression standard error. $\mathrm{F}$ ar is the LM F-test for serial correlation of up to fourth order. $\mathrm{F}$ arch is the fourth order ARCH F-test. $\chi^{2}$ nor is a Chi-square test for normality. $\mathrm{F}$ het is an $\mathrm{F}$ test for heteroscedasticity. Numbers in [•] are the $p$-values of the test statistics. $\Delta P_{t}^{U A}$ includes $\Delta P_{\{-1,-3\}}^{U A}, \Delta P_{\{-1\}}^{C O L}, \Delta P_{\{-1,-2\}}^{O M}, \Delta P_{\{-2\}}^{R O B}, d 1, d 2, d 893$ and a constant. $\Delta P_{t}^{C O L}$ includes $\Delta P_{\{-3\}}^{U A}, \Delta P_{\{-1,-2\}}^{C O L}, \Delta P_{\{-1,-2,-3\}}^{O M}, \Delta P_{\{-2\}}^{R O B}, d 1, d 2, d 893$ and a constant. $\Delta P_{t}^{O M}$ includes $\Delta P_{\{-1,-2,-3\}}^{U A}, \Delta P_{\{-1,-2\}}^{C O L}, \Delta P_{\{-1,-2\}}^{O M}, \Delta P_{\{-2\}}^{R O B}, d 1, d 2, d 893$ and a constant. $\Delta P_{t}^{R O B}$ includes $\Delta P_{\{-3\}}^{U A}, \Delta P_{\{-1\}}^{C O L}, \Delta P_{\{-1,-2,-3\}}^{O M}, \Delta P_{\{-1,-2,-3\}}^{R O B}, d 1, d 2, d 893$ and a constant. 
Table 2. Linearity tests on the residuals, BDS tests

Unwashed Arabica (UA)

\begin{tabular}{|c|ccc|ccc|ccc|ccc|c|}
\hline & \multicolumn{3}{|c|}{ Random Walk } & \multicolumn{3}{c|}{ Linear ECM } & \multicolumn{3}{c|}{ Polynomial ECM } & \multicolumn{3}{c|}{ Asymmetric ECM } \\
$m$ & \multicolumn{4}{|c}{$\varepsilon=$} & \multicolumn{4}{c|}{$\varepsilon=$} & $\varepsilon=$ & & \multicolumn{4}{c|}{$\varepsilon=$} \\
& 0.065 & 0.131 & 0.261 & 0.085 & 0.171 & 0.340 & 0.086 & 0.173 & 0.349 & 0.090 & 0.180 & 0.357 \\
\hline 2 & 0.000 & 0.033 & 0.351 & 0.069 & 0.026 & 0.020 & 0.039 & 0.110 & 0.436 & 0.003 & 0.003 & 0.010 \\
3 & 0.000 & 0.011 & 0.229 & 0.005 & 0.004 & 0.010 & 0.003 & 0.009 & 0.181 & 0.000 & 0.000 & 0.002 \\
4 & 0.000 & 0.002 & 0.283 & 0.002 & 0.000 & 0.005 & 0.000 & 0.001 & 0.118 & 0.000 & 0.000 & 0.001 \\
5 & 0.000 & 0.001 & 0.178 & 0.001 & 0.000 & 0.001 & 0.000 & 0.000 & 0.029 & 0.000 & 0.000 & 0.000 \\
6 & 0.000 & 0.000 & 0.178 & 0.001 & 0.000 & 0.001 & 0.000 & 0.000 & 0.013 & 0.000 & 0.000 & 0.000 \\
\hline
\end{tabular}

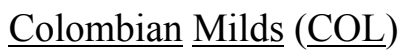

\begin{tabular}{|c|ccc|ccc|ccc|ccc|c|}
\hline & \multicolumn{3}{|c|}{ Random Walk } & \multicolumn{3}{c|}{ Linear ECM } & \multicolumn{3}{c|}{ Polynomial ECM } & \multicolumn{3}{c|}{ Asymmetric ECM } \\
$m$ & \multicolumn{4}{|c|}{$\varepsilon=$} & \multicolumn{4}{c|}{$\varepsilon=$} & \multicolumn{4}{c|}{$\varepsilon=$} & \multicolumn{4}{c|}{$\varepsilon=$} \\
& 0.062 & 0.124 & 0.247 & 0.083 & 0.167 & 0.336 & 0.082 & 0.166 & 0.334 & 0.083 & 0.167 & 0.335 \\
\hline 2 & 0.000 & 0.027 & 0.718 & 0.215 & 0.375 & 0.902 & 0.377 & 0.584 & 0.725 & 0.342 & 0.553 & 0.863 \\
3 & 0.000 & 0.012 & 0.842 & 0.014 & 0.063 & 0.858 & 0.005 & 0.143 & 0.866 & 0.007 & 0.147 & 0.442 \\
4 & 0.000 & 0.004 & 0.514 & 0.031 & 0.026 & 0.729 & 0.001 & 0.091 & 0.947 & 0.004 & 0.088 & 0.731 \\
5 & 0.000 & 0.001 & 0.300 & 0.007 & 0.005 & 0.569 & 0.000 & 0.027 & 0.745 & 0.000 & 0.025 & 0.517 \\
6 & 0.000 & 0.000 & 0.199 & 0.012 & 0.003 & 0.426 & 0.000 & 0.028 & 0.573 & 0.000 & 0.020 & 0.368 \\
\hline
\end{tabular}

$\underline{\text { Other Milds }} \underline{\underline{\mathrm{OM}})}$

\begin{tabular}{|c|ccc|ccc|ccc|ccc|c|}
\hline & \multicolumn{3}{|c|}{ Random Walk } & \multicolumn{3}{c|}{ Linear ECM } & \multicolumn{3}{c|}{ Polynomial ECM } & \multicolumn{3}{c|}{ Asymmetric ECM } \\
$m$ & \multicolumn{4}{|c|}{$\varepsilon=$} & \multicolumn{4}{c|}{$\varepsilon=$} & \multicolumn{4}{c|}{$\varepsilon=$} & \multicolumn{4}{c|}{$\varepsilon=$} \\
& 0.063 & 0.128 & 0.257 & 0.096 & 0.192 & 0.384 & 0.092 & 0.184 & 0.368 & 0.095 & 0.190 & 0.382 \\
\hline 2 & 0.000 & 0.036 & 0.255 & 0.243 & 0.180 & 0.847 & 0.141 & 0.163 & 0.937 & 0.026 & 0.057 & 0.849 \\
3 & 0.000 & 0.027 & 0.200 & 0.001 & 0.007 & 0.931 & 0.001 & 0.019 & 0.982 & 0.000 & 0.002 & 0.681 \\
4 & 0.000 & 0.008 & 0.077 & 0.000 & 0.003 & 0.749 & 0.001 & 0.015 & 0.678 & 0.000 & 0.001 & 0.400 \\
5 & 0.000 & 0.000 & 0.033 & 0.002 & 0.000 & 0.524 & 0.001 & 0.006 & 0.499 & 0.000 & 0.000 & 0.249 \\
6 & 0.000 & 0.000 & 0.019 & 0.006 & 0.000 & 0.338 & 0.001 & 0.002 & 0.380 & 0.000 & 0.000 & 0.150 \\
\hline
\end{tabular}

$\underline{\text { Robusta }}(\underline{\mathrm{ROB}})$

\begin{tabular}{|c|ccc|ccc|ccc|ccc|c|c|}
\hline & \multicolumn{3}{|c|}{ Random Walk } & \multicolumn{3}{c|}{ Linear ECM } & \multicolumn{3}{c|}{ Polynomial ECM } & \multicolumn{3}{c|}{ Asymmetric ECM } \\
$m$ & \multicolumn{4}{|c|}{$\varepsilon=$} & \multicolumn{4}{c|}{$\varepsilon=$} & \multicolumn{4}{c|}{$\varepsilon=$} & \\
& 0.071 & 0.141 & 0.280 & 0.081 & 0.162 & 0.323 & 0.076 & 0.153 & 0.307 & 0.078 & 0.158 & 0.318 \\
\hline 2 & 0.069 & 0.052 & 0.061 & 0.392 & 0.473 & 0.550 & 0.354 & 0.865 & 0.744 & 0.323 & 0.661 & 0.803 \\
3 & 0.005 & 0.047 & 0.031 & 0.326 & 0.708 & 0.687 & 0.157 & 0.568 & 0.825 & 0.215 & 0.738 & 0.677 \\
4 & 0.000 & 0.004 & 0.005 & 0.029 & 0.162 & 0.817 & 0.024 & 0.239 & 0.463 & 0.009 & 0.252 & 0.239 \\
5 & 0.000 & 0.000 & 0.002 & 0.000 & 0.007 & 0.304 & 0.031 & 0.060 & 0.145 & 0.000 & 0.034 & 0.060 \\
6 & 0.000 & 0.000 & 0.002 & 0.000 & 0.000 & 0.125 & 0.000 & 0.008 & 0.057 & 0.000 & 0.001 & 0.018 \\
\hline
\end{tabular}

Notes: The BDS test statistic tests the null hypothesis that a series is i.i.d. against the alternative of realisation from an unspecified non-linear process. $m$ is the embedding dimension and $\varepsilon$ equals $0.5 \sigma_{u}$, $1.0 \sigma_{u}$ and $2.0 \sigma_{u}$, respectively, where $\sigma_{u}$ is the standard deviation of the residuals. Given that the choices of $m$ and $\varepsilon$ are crucial for the power of the test, we report the results for different plausible values of $m$ and $\varepsilon$ as suggested by Brock, Hsieh and LeBaron (1991). Only $p$-values are reported. 
Table 3. Linearity tests on the residuals, Bicovariance and Tsay's test

\begin{tabular}{|c|l|cc|cc|}
\hline $\begin{array}{c}\text { Coffee } \\
\text { type }\end{array}$ & \multicolumn{1}{c|}{ Model } & \multicolumn{2}{c|}{ Bootstrap } & \multicolumn{2}{c|}{ Asymptotic Theory } \\
& & $\begin{array}{c}\text { Bicovariance } \\
l=7\end{array}$ & $\begin{array}{c}\text { Tsay } \\
k=5\end{array}$ & $\begin{array}{c}\text { Bicovariance } \\
l=7\end{array}$ & $k=5$ \\
\hline UA & Random Walk & 0.011 & 0.024 & 0.000 & 0.016 \\
UA & Linear ECM & 0.039 & 0.004 & 0.014 & 0.003 \\
UA & Polynomial ECM & 0.010 & 0.003 & 0.001 & 0.002 \\
UA & Asymmetric ECM & 0.016 & 0.002 & 0.003 & 0.001 \\
& & & & & \\
COL & Random Walk & 0.016 & 0.053 & 0.001 & 0.039 \\
COL & Linear ECM & 0.321 & 0.783 & 0.582 & 0.870 \\
COL & Polynomial ECM & 0.055 & 0.316 & 0.021 & 0.336 \\
COL & Asymmetric ECM & 0.690 & 0.997 & 1.000 & 1.000 \\
& & & & & \\
OM & Random Walk & 0.019 & 0.403 & 0.001 & 0.460 \\
OM & Linear ECM & 0.760 & 0.983 & 1.000 & 1.000 \\
OM & Polynomial ECM & 0.866 & 0.947 & 1.000 & 1.000 \\
OM & Asymmetric ECM & 0.869 & 0.939 & 1.000 & 1.000 \\
& & & & & \\
ROB & Random Walk & 0.027 & 0.165 & 0.005 & 0.186 \\
ROB & Linear ECM & 0.884 & 0.712 & 1.000 & 0.936 \\
ROB & Polynomial ECM & 0.161 & 0.350 & 0.206 & 0.390 \\
ROB & Asymmetric ECM & 0.197 & 0.426 & 0.273 & 0.478 \\
\hline
\end{tabular}

Notes: The Tsay (1986) test explicitly looks for quadratic serial dependence in the data and follows the $F$-distribution. Under the null hypothesis that a time series is a serially i.i.d. process, the Bicovariance test (Hinich, 1996), follows asymptotically the $\chi^{2}$ distribution. Following Ashley and Patterson (2001), both the bootstrap and the asymptotic theory $p$-values are reported and we set $k=5$ and $l=7$, where $k$ refers to the number of column vectors which contain all possible cross-products of the estimated residuals and $l=T^{0.4}$ where $T$ is the sample size. Only $p$-values are reported. 
Table 4 Forecast evaluation for the spot prices of various coffee types Forecast horizon $h=1$

Mean Absolute Error (MAE)

\begin{tabular}{|c|c|c|c|c|}
\hline $\begin{array}{l}\text { Coffee } \\
\text { type }\end{array}$ & $\begin{array}{c}\text { Random } \\
\text { walk }\end{array}$ & Linear ECM & Asymmetric ECM & Polynomial ECM \\
\hline UA & 0.140 & $0.120 \quad[0.160]$ & 0.119 [0.139] & $0.145 \quad[0.569]$ \\
\hline $\mathrm{COL}$ & 0.126 & $0.096 \quad[0.027]$ & $0.095 \quad[0.023]$ & $0.093 \quad[0.027]$ \\
\hline $\mathrm{OM}$ & 0.132 & $0.133[0.529]$ & $0.134 \quad[0.577]$ & $0.119 \quad[0.201]$ \\
\hline ROB & 0.098 & $0.110 \quad[0.788]$ & $0.092 \quad[0.314]$ & $0.095[0.420]$ \\
\hline
\end{tabular}

Mean Squared Error (MSE)

\begin{tabular}{|c|r|rr|rr|rr|}
\hline $\begin{array}{c}\text { Coffee } \\
\text { type }\end{array}$ & $\begin{array}{c}\text { Random } \\
\text { walk }\end{array}$ & \multicolumn{2}{|c|}{ Linear ECM } & Asymmetric ECM & \multicolumn{2}{|c|}{ Polynomial ECM } \\
\hline UA & 0.031 & 0.023 & {$[0.135]$} & 0.023 & {$[0.109]$} & 0.033 & {$[0.583]$} \\
\hline COL & 0.025 & 0.017 & {$[0.021]$} & 0.017 & {$[0.009]$} & 0.016 & {$[0.013]$} \\
\hline OM & 0.026 & 0.025 & {$[0.403]$} & 0.025 & {$[0.405]$} & 0.022 & {$[0.156]$} \\
\hline ROB & 0.014 & 0.019 & {$[0.888]$} & 0.014 & {$[0.556]$} & 0.015 & {$[0.675]$} \\
\hline
\end{tabular}

Notes: The forecasting period runs from 1996(2) to 2001(1). Figures in [•] contain the $p$ values for the forecast comparison statistic $D M^{*}$ of Diebold and Mariano (1995), as modified by Harvey et al. (1997), against the one-sided alternative that the MAPE (MSE) of the linear (asymmetric, polynomial) error correction model is less than the MAPE (MSE) of the random walk model. 
Figure 1. Coffee prices - Levels and first differences
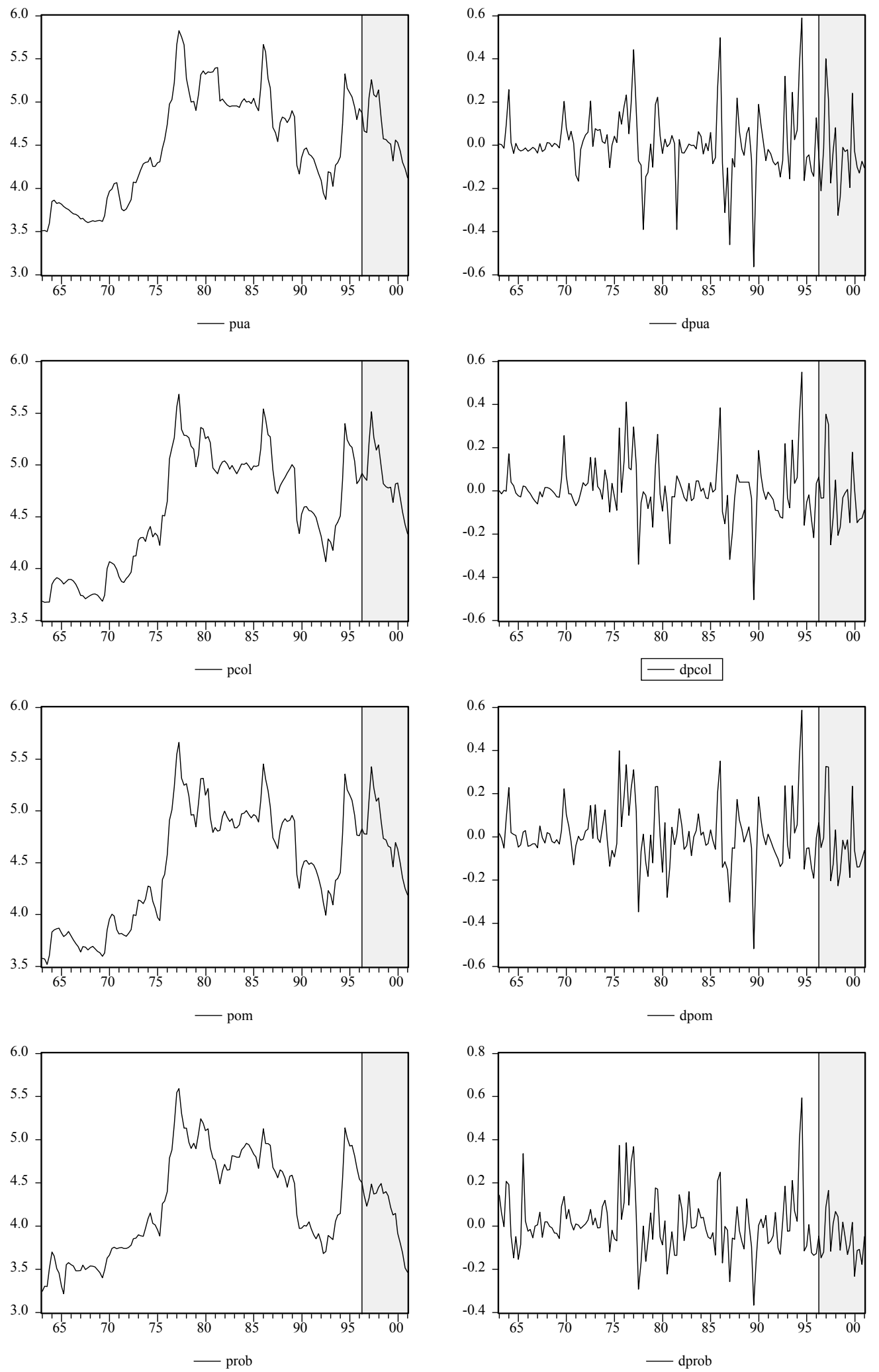

Note: Observations in the shadowed area are used for forecast comparison. 